\title{
Heidegger e a técnica como acabamento da metafísica e possibilidade de
}

um novo início

\section{Heidegger and Technology as metaphysical finishing and possibility of a new beginning}

\author{
Dr. Fábio Candido dos Santos \\ Universidade do Estado do Rio de Janeiro \\ fahbio@msn.com \\ https://orcid.org/0000-0003-3844-9033
}

\section{Resumo}

O presente artigo se propõe mostrar, a partir de uma seleção de textos de Heidegger acerca da técnica, como esta, derradeira manifestação da vontade de vontade e último estágio de desenvolvimento do pensamento metafísico, pode ser, a despeito de seu caráter corruptor do real, o único caminho para a reconexão do homem ao ser na sua relação originária com o ente. Entendida como "novo início" por Heidegger, esta configuração dependeria de uma recuperação do sentido originário de técnica

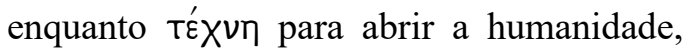
por meio do pensamento e da arte, a um retorno a si mesma e aos entes como possibilidades e não mais enquanto objetos indiferenciados de domínio e exploração da técnica. A título de fundamentação, a tarefa em questão também se compromete a discutir os princípios histórico-metafísicos da técnica, resguardados na evidenciação da identidade entre niilismo e metafísica e do estabelecimento do cogito como fundamento ôntico-ontológico do real na modernidade.

\begin{abstract}
This article aims to show, based on a selection of Heidegger's texts about the technique, as this, the ultimate manifestation of the will to will and the last stage of development of metaphysical thought, may be, despite its corrupting character of the real, the only way to reconnect man to Being in his original relationship with the being. Understood as a "new beginning" by Heidegger, this configuration would depend on a recovery of the original sense of technique as T'́x $X V \eta$ to open humanity, through thought and art, to a return to itself and to beings as possibilities and no longer as undifferentiated objects of mastery and exploration of technique. As a basis, the task in question also undertakes to discuss the historical-metaphysical principles of the technique, safeguarded in the disclosure of the identity between nihilism and metaphysics and the establishment of the cogito as an ontic-ontological foundation of the real in modern times.
\end{abstract}

Palavras-chave: Heidegger. Técnica. Metafísica. Novo Início. Niilismo. Cogito.

Keywords: Heidegger. Technology. Metaphysics. New beginning. Nihilism. Cogito. 


\section{I - Do niilismo à técnica}

Se por um lado Nietzsche (2008, p. 23) previu que o niilismo dominaria o ocidente por duzentos anos como consequência da morte de Deus e do vácuo que este deixava, Heidegger, por outro, pensava o niilismo como um fenômeno mais amplo e resultante da manifestação da história do ser enquanto metafísica. Para o autor de Ser e tempo, o niilismo não se iniciava com o pensamento moderno da subjetividade que representa objetos, mas ainda na antiguidade, no momento de ruptura com o acordo originário ${ }^{1}-0$ ó Aristóteles, ou seja, a partir da instalação da metafísica. A idade média e o mundo moderno, a propósito, não passam de reelaborações daquela ruptura originária.

De fato, o niilismo, para Heidegger, é a própria metafísica e não se resume à sua porção moderna, como acreditava Nietzsche (HEIDEGGER, 2002c, p. 266-267). O fenômeno, e a exemplo do que previu o autor de Zaratustra, não se esgota com a modernidade, prolongando-se, contudo, para os séculos seguintes, uma vez que o pensamento metafísico, mesmo em seu acabamento, manteria sua hegemonia por meio de sua derradeira manifestação: a técnica. O que Nietzsche chamava exclusivamente de niilismo, isto é, da supremacia daquele fenômeno na Europa dos próximos dois séculos, Heidegger viu como manifestação do domínio da técnica, cuja influência não era, como pensava Nietzsche, regional, mas, ao contrário, planetária, e de escopo diferente do niilismo "clássico".

A técnica marcaria, segundo Heidegger, o ápice de desenvolvimento da metafísica entendida como niilismo do ponto de vista da história do ser. O pensador encara este estágio como clímax por reconhecer nesta nova configuração metafísica um risco não apenas aos entes em geral, mas sobretudo para a própria essência do homem, como será

\footnotetext{
${ }^{1}$ Heidegger defende esta tese quando afirma, em seu Heráclito, ser a metafísica o resultado de uma mudança de postura do homem em relação ao real, originalmente de compreensão (ausculta) e que, a partir do surgimento de um Eros pelo saber, nas especulações de Sócrates, Platão e Aristóteles, se transforma em um desejo ou vontade de conhecimento cujo único interesse é o de controle do real. A materialização desta inclinação dar-se-á como metafísica, ou seja, como resultado da institucionalização daquela vontade em nome da perscrutação do ente enquanto entidade. Instala-se, neste momento o esquecimento do ser, isto é, a metafísica. Cf. HEIDEGGER, M. Heráclito. Rio de Janeiro: Relume Dumará, 2002.
} 
demonstrado em seguida. Nietzsche, no entanto, não chegou a prever esta estruturação, mas pôde entender aquilo que a motivou e ajudar a preparar o caminho para as especulações de Heidegger que, desta forma, logrou mostrar que o pensamento motor da contemporaneidade é, sem sombra de dúvida, aquele do domínio de uma concepção técnica do real. Antes, contudo, de discutir o poderio desta configuração para o mundo moderno e contemporâneo, faz-se necessário compreender seu liame com a tradição metafísica, visando encontrar as razões que motivaram seu aparecimento no horizonte da modernidade.

A essência da técnica encontra suas raízes no mundo moderno, mais especificamente a partir da descoberta do cogito. De fato, todo o problema contemporâneo se alicerça nas especulações de Descartes e na concepção de mundo trazida por suas considerações, embora o próprio pensador francês fosse ele mesmo o resultado de uma história iniciada ainda na antiguidade (GILSON, 1930). O decisivo, no entanto, é observar que por detrás da estrutura encontrada por Descartes, encontra-se seu verdadeiro motor: a vontade. É ela quem possibilita o estabelecimento da iustitia resultante de adequatio entre sujeito e objeto, ou seja, da veritas como certeza. A representação, que possibilita a contraposição dos polos sujeito e objeto, congrega, em si, estruturas ônticas humanas para se efetivar. Kant, mais tarde e na esteira de Descartes, as chamou de estruturas a priori da subjetividade na Crítica da razão pura. De uma forma ou de outra, a objetividade depende da certeza e do asseguramento da subjetividade fundada na vontade, que Heidegger chama de vontade de vontade e expõe suas estruturas em uma reveladora nota não publicada do final da década de 30 e organizada tardiamente com outros escritos sob o sugestivo título de $O$ acontecimento apropriativo:

\footnotetext{
O estágio prévio da vontade de vontade é a "vontade de poder". A vontade de vontade é a vontade que quer a si mesma. O que quer a vontade? $\mathrm{O}$ querer. $\mathrm{O}$ que é isso? O trazer-se-para-diante-de-si do re-presentável. Esse é o todo dos objetos; os objetos são o ente no interior da verdade da certeza, isto é, do dispor-se de algo constatado. A pura objetivação calculadora determina o ser do ente como objetividade. Na medida, porém, em que essa objetivação é vontade de vontade, o ser mesmo tem a essência da vontade. A vontade de vontade é aquilo que se submete a si mesmo como o fundamento de si mesmo, isto é, o sujeito (HEIDEGGER, 2013, p. 111).
}

As frases que abrem e terminam a nota condensam e explicam com precisão o modus operandi da modernidade e seu objetivo primeiro: poder. Não por outra razão Heidegger deriva a vontade de vontade da vontade de poder de Nietzsche (HEIDEGGER, 1991, p. 
63), uma vez que defende polemicamente a identidade entre poder, vontade e niilismo no pensamento nietzschiano, acusando o filósofo de ser, por este motivo, tão metafísico quanto a tradição que acredita criticar (HEIDEGGER, 2002b, p. 68). Afinal, se Nietzsche proclama, por meio de seu elogio da vontade de poder, o controle do real, como defende Heidegger, ele realmente se filia à tradição e faz parte da metafísica, como, de fato, seu último representante ${ }^{2}$. Independentemente da posição de Heidegger sobre Nietzsche, o que interessava, contudo, à vontade subjacente ao cogito era a certeza e segurança que proveria o domínio e o controle absolutos sobre o real, ou seja, todo o poder de manipulação dos entes ao sujeito. O advento da técnica não passa do aprofundamento e da chegada à plenitude deste projeto moderno.

Em A superação da metafísica, texto elaborado entre 1936 e 1946, e que discute o acabamento da resposta ocidental à questão do ser e de sua ligação com o aparecimento do domínio da técnica, Heidegger afirma que "a vontade de querer é a consciência suprema e incondicional do auto-asseguramento calculador de todo cálculo de si mesma" (HEIDEGGER, 2002b, p. 77), ou seja, em toda ação da subjetividade objetivadora, encontra-se subjacente a operação de uma vontade que se assegura dos resultados representações - dela mesma. Dessa forma, o objeto não passa do querer da subjetividade com o qual se calcula a priori, isto é, com a correção e exatidão daquilo mesmo que é o ente. Para Heidegger,

A exatidão da vontade de querer é o asseguramento completo e incondicional de si mesma. O que para ela é querer mostra-se correto, exato e em ordem porque a própria vontade de querer permanece a única ordem. Nesse autoasseguramento da vontade de querer perde-se a essência originária da verdade. A correta exatidão da vontade de querer é pura e simplesmente o nãoverdadeiro. [...] $\mathrm{O}$ correto e exato domina o verdadeiro e marginaliza a verdade. A vontade do asseguramento incondicional faz aparecer a insegurança em todos os níveis (HEIDEGGER, 2002b, p. 76-77).

A vontade de querer para se estabelecer como fundamento do real, mascara a verdade em certeza, segurança e correção, ou seja, veritas. É preciso, contudo, relembrar que a

\footnotetext{
${ }^{2}$ Segundo Ernildo Stein, o que Heidegger quer dizer é que "a essência do niilismo não se situa na metafísica de Nietzsche, mas na própria metafísica. A metafísica enquanto metafísica é o autêntico niilismo. A essência do niilismo é historicamente como a metafísica. A metafísica de Platão não é menos niilismo que a metafísica de Nietzsche. Naquela, a essência do niilismo fica apenas escondida; nesta, ela se manifesta". Cf. STEIN, E. Introdução ao Pensamento de Martin Heidegger. EdiPUCRS: 2011, p. 125.
} 
verdade à qual alude Heidegger é ỏ $\lambda \eta \theta_{\varepsilon \varepsilon ı \alpha}$ o desencobrimento que possibilita que o ente seja em seu ser. Verdade como adequação, como o filósofo havia demonstrado originalmente no $\S 44$ de Ser e tempo, não passa de um evento epigonal e derivado do desvelamento. É, contudo, em Platão: O Sofista, texto que congrega o curso ministrado pelo pensador no semestre de inverno de 1924-25 e, portanto, do mesmo período de sua obra fundamental, que a questão é aprofundada. Heidegger defende que $\alpha^{\lambda} \lambda \eta^{\prime} \theta \varepsilon ı \alpha$ é, no fundo, $\alpha$ - $\lambda \eta \eta \dot{\theta} \theta \varepsilon ı \alpha$, ou seja, não-esquecimento, não-encobrimento. De fato, o que o a privativo quer dizer é que algo falta ou que simplesmente foi retirado. $A^{\lambda} \lambda \eta^{\prime} \theta \varepsilon ı \alpha$ significa tirar o ente do velamento, do esquecimento:

\begin{abstract}
$\alpha_{\alpha} \lambda \hat{\theta} \theta \varepsilon ı \alpha$ quer dizer: não estar mais escondido, ser descoberto. Essa expressão privativa indica que os gregos tinham algum entendimento do fato de que o descobrimento do mundo tinha de ser arrancado à força, que é, inicialmente, e na maioria das vezes, indisponível. $O$ mundo é primariamente, se não completamente, oculto. [...] $\mathrm{O}$ mundo é descoberto apenas no círculo imediato do mundo circundante, na medida em que as necessidades naturais requerem. E precisamente aquilo que em consciência natural era, dentro de certos limites, talvez originalmente descoberto se torna amplamente coberto de novo e distorcido pelo discurso. Opiniões se solidificam elas mesmas em conceitos e proposições; elas se tornam truísmos que são repetidos diversas vezes, com a consequência de que aquilo que foi originalmente descoberto volta a se encobrir de novo. Assim, o ser-aí cotidiano se move em um duplo encobrimento: inicialmente em mera ignorância e, então, em um encobrimento muito mais perigoso à medida em que o falatório transforma o que foi descoberto em inverdade (HEIDEGGER, 2003b, p. 11).
\end{abstract}

A verdade proposicional oriunda da adequação entre sujeito e objeto expressa pelo discurso "correto" da representação é, com efeito, uma derivação de uma verdade mais fundamental e que precede essencialmente o juízo. Essa verdade des-cobre o ente em seu

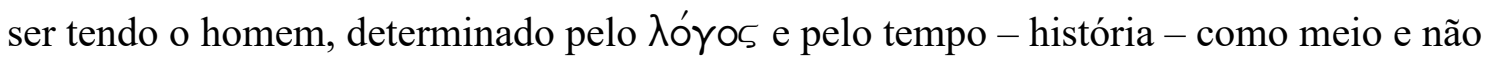
fim. O $\alpha^{\lambda} \lambda \eta \theta \varepsilon \cup ́ \varepsilon ı \nu$ - ou desencobrir - se dá de diversas maneiras e possibilidades, mas

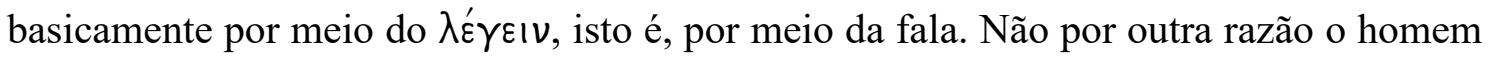

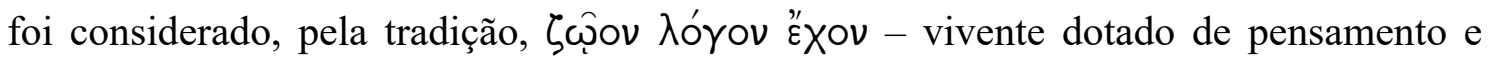
linguagem ou, simplesmente, animal rationale. A descoberta, contudo, deve ser perdida seja via desgaste da opinião ou pela insistência da ignorância para, no futuro, ser re-descoberta de acordo com as necessidades práticas e temporais do homem e renovando, destarte, a existência em forma de acontecer, ou seja, como história. É por esta razão que, ainda no $\$ 44$ de Ser e tempo, Heidegger (2012b, p. 617) afirma que "o Dasein já é cada vez na verdade e na não-verdade", uma vez que viver é estar sempre encobrindo e 
descobrindo os entes, ou seja, elaborando e reelaborando compreensões do real por meio de várias formas de $\alpha \dot{\alpha} \eta \eta \varepsilon v$ Eı v. Assim se mostra e se organiza a realidade fundamentalmente. O que a vontade de querer, em seu afã de ordenação, ambiciona, é a completa subversão do caráter originário desta estrutura em busca do controle do incontrolável: a vida. Essa vontade não é, como se pensaria ingênua e apressadamente, dependente do homem. "Na verdade", diz Heidegger (2002b, p. 77), "é o homem quem é querido pela vontade de querer, sem se dar conta da essência dessa vontade". Essa essência é a tendência histórica imposta pelo cogito, isto é, pela subjetividade que representa objetos, e seu interesse em dominar o real a partir do autoasseguramento na correção e na exatidão da veritas. $\mathrm{O}$ homem não cria essa tendência, mas esta, ao contrário, dele se utiliza para se efetivar. No entender de Heidegger, o homem não controla o ritmo da história porque não é da competência de seu ser aquele movimento. Ele é, no máximo, o local por onde a história se dá e nada mais.

A hegemonia da vontade de querer é resultado, segundo Heidegger, do fato de o homem "deixar o ser", ou seja, esvaziá-lo em função do interesse de controle do ente por meio da substituição do ser pela entidade, cuja configuração encontra expressão na estrutura do cogito. Essa decisão, que equivale em Nietzsche à morte de Deus, instaura o niilismo e propicia o aparecimento de sua versão mais radical: o domínio da técnica. Esta, como observa Heidegger, é inseparável do motor do pensamento moderno:

\footnotetext{
A vontade de querer institucionaliza assim como ser o próprio ente. Somente na vontade de querer podem predominar a técnica (asseguramento da consistência) e a ausência incondicional de meditação (vivência) (HEIDEGGER, 2002b, p. 75).
}

Mas o que vem a ser exatamente o domínio da técnica? Não se resume aos mecanismos e máquinas, embora também façam parte dela. A essência da técnica moderna não é, segundo Heidegger, nada de técnico (HEIDEGGER, 2002a, p. 11). O mesmo vale para a tecnologia como um todo. Dessa forma, é preciso, antes de se tratar da técnica moderna, compreender o técnico em sua essência. Para Heidegger, técnica

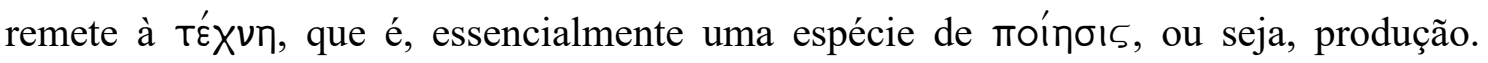
Produzir, no entender do pensador alemão, é conduzir do encobrimento para o desencobrimento, isto é, descobrir o ente em seu ser. Tal "procedimento" é, mais uma

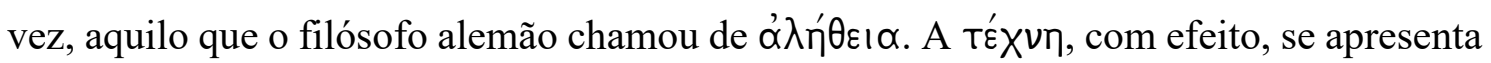


como uma das possibilidades de aparecimento dos entes ao homem - $\alpha^{\lambda} \lambda \eta \theta \varepsilon u ́ \varepsilon I \nu$ - como também o era, e Aristóteles o demonstrou em sua Metafísica, a દ̇тı

Nesta perspectiva, Heidegger conclui que a técnica é, essencialmente, desencobrimento. Seu papel originário é poiético, ou seja, visava ao desbravamento do real em seu ser. Fica, contudo, em aberto como a Té $\chi \nu \eta$ teria se transformado em técnica moderna e como se compatibilizaria com a vontade de querer. Em A questão da técnica, de 1953, Heidegger se impõe a tarefa de responder este questionamento ao expor o que vem a ser a essência da técnica moderna. Para o filósofo, ela não passa de uma armação ou composição (Ge-stell), que "significa a força de reunião daquele por que põe, ou seja, que desafia o homem a des-encobrir o real no modo da dis-posição, como disponibilidade. Ge-stell denomina, portanto, o tipo de desencobrimento que rege a técnica moderna" (HEIDEGGER, 2002a, p. 24). Nesta dimensão da questão, Gilvan Fogel mostra, por meio de um conhecido mito, a conexão da técnica com o cogito, sua verdadeira medida:

\footnotetext{
"Gestell” diz o modo como, na hodierna técnica, se concretiza a estruturação do "cogito". É que "Gestell", dizendo "esquema", "enquadramento", “armação", fala, na verdade, do leito de Procusto, que é o cogito, enquanto substância, representação e certeza: tudo, por antecipação, está pré- e pro-posto no fundo, no horizonte do cogito, que é controle e auto-asseguramento prévios (FOGEL, 1999, p. 160).
}

A técnica moderna desafia o homem a explorar a natureza, extraindo, transformando, distribuindo e estocando seus recursos com o mero objetivo de dispor deles em função do interesse de assegurar o controle por meio da operação "armadora" do cogito, "pois controle e segurança constituem até as marcas fundamentais do desencobrimento explorador" (HEIDEGGER, 2002a, p. 20). O “desafio" nada mais é do que a operação sub-reptícia da vontade de querer na forma do desejo de consumo dos entes para a reserva e o armazenamento da energia retirada da natureza para a pura disponibilidade de uso e ab-uso do homem, ele mesmo à disposição desta ordem estrutural enquanto condicionado pela técnica, à moda do leito de Procusto. Nesta configuração de exploração e consumo, o objeto de pesquisa é exaurido até que desapareça no não-objeto da disponibilidade, uma vez que o ente, isto é, sua forma de aparecimento se reduz ao mero dispor-se para o uso e o ab-uso, obscurecendo quaisquer outros sentidos de ser que o mostrem ao homem. 
A configuração do ente não se dá mais como o contraposto ao sujeito, mas, sob a técnica, enquanto o que está disponível para o uso. Essa estruturação só é possível no vácuo do ser, preenchido pela vontade de querer no mecanismo de mobilização dos processos de ordenamento e organização ditados e mantidos pela técnica moderna:

\section{A devastação da terra começa como processo voluntário, mas que, em sua essência, não é e nem pode ser sabido. Começa no momento em que a essência da verdade se circunscreve como certeza na qual a representação e a produção humanas asseguram-se de si mesmas (HEIDEGGER, 2002b, p. 86).}

A essência da técnica se engendra no movimento das ciências modernas da natureza - tendo a física à frente - e seu caráter experimental, que, por conta de sua composição puramente técnica a priori, precisa dispor do experimento para testar se a natureza confirma suas especulações. Essa disposição da natureza - do real - aos interesses humanos de controle operados pela subjetividade movida pela vontade de querer enseja a configuração de mera disponibilidade técnica dos entes como reservatório de energia, reconfigurando o mundo e seus sentidos. Aqui, segundo Heidegger, reside o que o pensador chama de "maior perigo" (HEIDEGGER, 2002a, p. 29). Desde Ser e tempo ${ }^{3}$, o filósofo defende a tese de que o homem, ou melhor, o Da-sein - o ser-aí que existe - é o lugar de aparecimento do ser, ou seja, é também o aí do ser por meio da abertura ao real efetivada pela capacidade essencial de pensamento e linguagem submetidos ao tempo. O aparecer do ser, contudo, se dá no ente, descobrindo-o no movimento de tirá-lo do esquecimento por meio dos humores (Stimmung) e de sua relação com o גóyos na estrutura da abertura (Erschlossenheit). Isso já foi demostrado como constituinte de configuração da $\alpha^{\prime} \lambda \eta^{\theta} \theta \varepsilon ı \alpha$. O homem é, com efeito, o seu aí, ou seja, a sua abertura para o mundo. Viver nada mais é do que a liberdade de se relacionar com ele por meio do caráter essencial de desencobrimento humano. Esta configuração fíca comprometida com a instauração da técnica moderna e a ditadura de apenas uma forma de desencobrimento do real: o ente como disponibilidade. Para Heidegger, esse é o verdadeiro perigo do abandono do ser promovido pela vontade de querer ao estabelecer os critérios de exploração do real ainda na estruturação das ciências da natureza:

Se, porém, o destino impera segundo o modo da com-posição (Ge-stell), ele se torna o maior perigo, o perigo que se anuncia em duas frentes. Quando o descoberto já não atinge o homem, como objeto, mas exclusivamente, como

\footnotetext{
${ }^{3}$ Do $\$ 28$ a ao 38.
} 
disponibilidade, quando, no domínio do não-objeto, o homem se reduz apenas a dis-por da disponibilidade - então é que chegou à beira do precipício, lá onde ele mesmo só se toma por dis-ponibilidade. E é justamente esse homem assim ameaçado que se alardeia na figura do senhor da terra. Cresce a aparência de que tudo que nos vem ao encontro só existe à medida que é um feito do homem (HEIDEGGER, 2002a, p. 29).

A técnica não encobre apenas outros tipos de $\alpha^{\lambda} \lambda \eta \theta \varepsilon u ́ \varepsilon ı 1 \nu$ - desencobrimentos - como, por exemplo, aquele que se mostra na тoínoıs, mas o próprio descobrir enquanto tal. De fato, o domínio da técnica traz a ameaça - o perigo - de se interditar ao homem a possibilidade da própria verdade: $\alpha^{\prime} \lambda \eta^{\theta} \theta \varepsilon ı$. A relação dos homens com os entes encontrar-se-iam limitadas ao consumo ab-usivo voltado para a extração e o armazenamento de energia para fins de controle e poder. De fato, o que Heidegger quer mostrar é que nenhuma outra forma de abertura do real ao homem será possível se a técnica triunfar absolutamente. $\mathrm{O}$ contexto político mundial é o melhor exemplo desta ameaça. A técnica não é "privilégio" do ocidente, do oriente ou de qualquer área específica do globo, mas do planeta como um todo, uma vez que suas nações componentes se pautam pela lógica da exploração dos recursos da natureza para alcançar o poder. O que foram as últimas guerras senão a disputa pelo domínio de riquezas e bens para a hegemonia político-econômica mundial? A Guerra Fria, um conflito indireto entre Estados Unidos e a extinta União Soviética, não era apenas um embate norteado pela luta entre capitalismo e socialismo, mas pela disputa pelo poder de hegemonia no manuseio dos entes. O objetivo dos sucessivos conflitos no oriente médio se mostra ainda mais claro neste particular, pois tem apenas um alvo: o petróleo, cujo uso exemplifica perfeitamente o caráter de disponibilidade preconizado pela essência da técnica. Como resultado, afirma Heidegger, o mundo contemporâneo observa uma franca uniformidade humana e do ente em geral, pautada pela técnica e seu fundamento na vontade de querer:

\begin{abstract}
A uniformidade não é a consequência, mas o fundamento dos conflitos armados entre os vários pretendentes à hegemonia do abuso dos entes, com vista a assegurar seu ordenamento. A uniformidade de tudo o que é e está sendo tem origem no vazio provocado quando se deixa o ser. Visa apenas assegurar, por meio dos cálculos, sua própria ordem, à qual está subordinada à vontade de querer. [...] Porque a realidade consiste na uniformidade do cálculo planificador, o homem também deve passar a uniformizar-se para dominar o real (HEIDEGGER, 2002b, p. 84).
\end{abstract}

O niilismo originado pelo abandono do ser esvaziou as diferenças entre os entes e os nivelou a simples matéria prima para o consumo e o ab-uso. $\mathrm{O}$ agente desta história - o 
homem - também um ente, sofreu a mesma metamorfose e não se diferencia neste cenário de equalização e achatamento nadificante. Este horizonte é pintado por Heidegger como o de "acabamento da metafísica" (HEIDEGGER, 2002b, p. 84). Ou seja: o domínio da técnica é o último estágio de desenvolvimento metafísico, uma vez que se mostra como a radicalização total e irrestrita do esquecimento do ser em função da tomada da entidade como medida do real, concretização plena do projeto da vontade de vontade iniciada com Platão e Aristóteles.

$\mathrm{O}$ esquecimento, historicamente, cresce à medida que o apreço pela entidade do ente se aprofunda e não mais se satisfaz em obscurecer o ser, mas, com efeito, em lhe bloquear o caminho de aparecimento de sua verdade. A técnica é a materialização deste momento, pois se configura como redução do real à disponibilidade para uso e afasta qualquer outra manifestação do ser. Ao homem, dominado pela vontade de querer que move a técnica, resta a errância e o trabalho em meio ao real nivelado:

Como animal rationale ou, hoje em dia, como o ser vivo trabalhador, o homem deve errar pelo deserto da desolação da terra. [...] $\mathrm{Na}$ ordem metafísica hodierna, o trabalho alcançou a objetivação incondicional de todo vigente que vigora na vontade de querer (HEIDEGGER, 2002b, p. 62).

Sob o signo da Ge-Stell, da armação que essencializa a técnica, o homem, que já foi um animal calculador, se transforma em instrumento da vontade de querer, isto é, curva-se ao trabalho, ficando à disposição do dispor da técnica. O desafio por exploração, armazenamento de recursos e controle da natureza depende do trabalho humano e de sua total ausência de meta para além do mero meio para a disponibilidade do disponível. Neste cenário, é o homem a principal matéria prima, pois é o sujeito, o local por onde a vontade de querer pode se querer e dispor o homem e todos os entes à disponibilidade do consumo, do uso e do abuso para a consolidação do poder.

Essa ordem - planetária - independe, como já mencionado, da vontade individual do homem e se apresenta, na contemporaneidade pós-Guerra Fria e exclusivamente por meio do capitalismo, como trabalho para o consumo de entes "descartáveis". O trabalho na época da técnica perde o seu caráter existencial e se torna uniforme, uma vez que tem no uso dos entes o seu único fim. Não por outra razão "o animal trabalhador abandonase à vertigem de seus poderes e feitos a fim de se descarnar e aniquilar-se no nada aniquilador" (HEIDEGGER, 2002b, p. 63). O homem não percebe porque e para quem 
trabalha ao acreditar ingenuamente que vende suas competências para o Estado ou mesmo para a iniciativa privada. Aqui Heidegger se aproxima da concepção de Marx de trabalho alienado, exposta pelo último nos Manuscritos econômicos-filosóficos, de 1844, nos quais o maior crítico do capitalismo mostra que o trabalhador perde o objeto de seu trabalho "em favor de um poder estranho, de um homem estranho" (MARX, 1993, p. 171). Claro que, no caso de Marx, a questão diz respeito, ainda que preliminarmente, ao modus operandi de uma estrutura do capital, mas sua "lógica" converge para a argumentação de Heidegger ao fazer ver a ignorância do homem em relação àquilo que o domina socioeconomicamente. Marx denunciou o problema onticamente; Heidegger encontrou sua origem.

A alienação também opera em outro nível, mais sutil e preciso e de maneira a consolidar o poder inebriante do supracitado: o do passatempo do entretenimento. $\mathrm{O}$ objetivo, neste caso, é encobrir o tédio de uma existência errante nos domínios da "desertificação da terra" - do esvaziamento do ser mesmo - sob a figura da ordem incondicionada do ordenar do ente. Se o trabalho aliena, sua repetição entedia e, com o objetivo de controlar este último, o passatempo do entretenimento é oferecido como forma de manter a engrenagem da armação técnica - o homem - "girando" infinitamente.

Duas obras cinematográficas pop norte-americanas do fim do século XX, ambas coincidentemente do ano de 1999, lançam uma luz sobre as consequências da questão da técnica e do trabalho para o homem em uma linguagem pouco convencional e estrategicamente elaborada para agradar tanto a públicos insipientes quanto àqueles mais intelectualizados. Tidas como "cult" nos dias atuais, Matrix (The matrix) e Clube da luta (Fight club) utilizaram de uma estrutura ao mesmo tempo não-linear e subliminar para expor problemas suscitados pelo domínio da técnica na contemporaneidade. Matrix, o primeiro a ser exibido, ganharia ainda mais duas sequências, embora o original seja o mais contundente do ponto de vista filosófico. A trama narra o momento posterior a uma guerra entre homens e máquinas que ganharam consciência. Derrotados, os homens aguardam a chegada de um messias que pode subverter o cenário e libertá-los do jugo dos adversários. Ocorre que essa luta não é exatamente "bélica", uma vez que o poder das máquinas reside justamente na fraqueza do homem, fonte de energia dos próprios opressores. A fraqueza, com efeito, nada mais é do que a leniência, a letargia diante daquilo que é próprio do homem: o pensar. A matrix, neste cenário, não passa do modo 
pelo qual a dominação das máquinas se realiza. No lugar do real - aquele presidido pelo ser - apresenta-se outro, artificial, feito para dominar e colocar a humanidade à disposição, exatamente como Heidegger apresenta o terreno sobre o qual a contemporaneidade se move. O messias é o instante de quebra desta configuração e a consequente possibilidade de libertação dos homens. Nada mais cristão, embora revele esteticamente como o homem atual depende de máquinas e telas e se aliene de si mesmo em função de uma lógica de produção e controle, vendo a realidade exclusivamente como mera disponibilidade e sendo inconscientemente consumido por ela. Em um diálogo no início do filme entre o personagem Morpheus e o protagonista Neo, é possível entender como a tecnologia criou para o homem uma prisão refinada da qual só se pode escapar se algo inesperado realmente acontecer. Morpheus expõe resumidamente a Neo o que está em jogo:

\begin{abstract}
A matrix está em todo lugar. Está à nossa volta. Mesmo aqui, exatamente nesta sala. Você pode vê-la quando olha pela janela ou quando liga a sua televisão. Você pode senti-la quando vai para o trabalho... Quando vai à Igreja... Quando paga suas contas. Ela é o mundo que foi colocado diante dos seus olhos para cegá-lo da verdade. [Qual?] Que você é um escravo, Neo. Como todos os outros, você nasceu em um cativeiro. Nascido em uma prisão que você não pode cheirar, provar ou mesmo tocar. Uma prisão para sua mente (MATRIX, 1999).
\end{abstract}

Neo, "novo" em latim e ao mesmo tempo anagrama de "the one" em inglês ou "o escolhido" em português, representa o acontecimento extraordinário - o milagre - que deve ocorrer para que a ordem estabelecida se desfaça sob a emergência de uma nova, ou seja, a deposição do domínio do ente em função do ser. Na ausência deste acontecimento, os homens continuam sua errância na desertificação da terra promovida pelo trabalho imposto pela Ge-stell que os consome por meio do alienante fomento ao passatempo e ao consumo. Se a maioria se mostra aprisionada pela armação da técnica moderna, alguns poucos, como os resistentes de Matrix, estão “acordados" para aquela ordem, embora impotentes. Esse - a impotência - é o tema de Clube da luta, lançado apenas cinco meses após a obra das irmãs Wachowski. O filme gira em torno do personagem-narrador, que se mostra profundamente insatisfeito com a vida produtivista e consumista na qual se encontra, embora não se dê conta disso inicialmente. Dentro dele uma luta existencial opõe uma vida "apolínea" - aquela de necessidade de trabalho e consumo de acordo com a lógica social - a outra "dionisíaca", que quer dar vazãoao lado instintivo do homem e 
se volta violentamente contra tudo aquilo que a reprime. Esta última, com efeito, faz aparecer um alter-ego do personagem-narrador, o "liberado" Tyler Durden, com o qual aquele vai lutar (psicologicamente) ao longo da trama. Durden, com efeito, é uma espécie de anti-herói niilista que condena todos os valores da sociedade de consumo e que vai tentar destruí-la ao final da obra. Inconformado com a superficialidade da existência promovida pelo binômio trabalho-consumo, o narrador vai aos poucos se deixando dominar pelo lado instintivo, abandonando tudo o que havia amealhado para dar um sentido "espiritual" à sua existência. A luta física que dá nome à obra cinematográfica é o elemento que o abre para a vida, até então esvaziada pelo non sense existencial do produtivismo do trabalho. Em uma das muitas falas filosóficas de Durden, todo o malestar com a situação atual é exposto com contundência nietzscheana:

\begin{abstract}
A propaganda nos faz perseguir carros e roupas, trabalhar em empregos que detestamos para comprarmos porcarias que não precisamos. Somos as crianças do meio da história, cara. Sem propósito ou lugar. Não temos Grande Guerra. Nem Grande Depressão. Nossa Grande Guerra é espiritual... Nossa Grande Depressão são nossas vidas. Fomos todos criados pela televisão para acreditar que um dia todos seríamos milionários, deuses do cinema e estrelas do rock. Mas não seremos. E estamos lentamente descobrindo este fato. E estamos muito, muito chateados (CLUBE DA LUTA, 1999).
\end{abstract}

O homem da técnica moderna, que trabalha movido pela vontade de querer em explorar a natureza e tornar seus recursos meramente disponíveis para uso e ab-uso, é uma presa fácil para os meios de comunicação de massa, estrutura de manutenção da própria técnica que o mantém ocupado em adquirir o que é produzido ou distraído com o entretenimento e, consequentemente, fechado para a situação na qual se encontra. Em Matrix, Morpheus diz que a "matrix" é um sistema de computador que foi criado para controlar a humanidade, transformando o homem em sua fonte de energia. No Clube da luta, esse papel é preenchido pela publicidade, cujo interesse se funda em vender segundo interesses empresariais e, logo, de produção e consumo. O personagem narrador, cansado de errar na desertificação promovida pelo trabalho dirigido pela técnica, se insurge e tenta instaurar um novo tipo de vida, que, contudo, não lhe é permitida ao final da trama muito provavelmente porque o filme é estadunidense, epicentro do consumo e do entretenimento. Ou seja: a questão da exaustão com este tipo de cultura é apresentada, mas não é levada às últimas consequências. De qualquer forma, ambas as obras cinematográficas buscam, cada uma a seu modo, mostrar esteticamente o contexto no 
qual o homem contemporâneo se encontra e toda a dificuldade que se apresenta ao se pensar qualquer possibilidade de subversão da lógica institucionalizada pela técnica.

Diante deste cenário desolador, o que resta ao homem do acabamento da metafísica? Na entrevista concedida à revista Der Spiegel, em 1966, Heidegger defende que a saída para a situação do homem contemporâneo encontra-se na própria ameaça que tanto o assola:

Ge-stell significa isso: o homem sofre o controle, a exigência e a injunção de uma potência que se manifesta na essência da técnica. É justamente na experiência que o ser humano faz de ser assim convocado e requisitado (gestellt) por qualquer coisa que ele não é e que ele próprio não domina, que descobre a possibilidade de compreender que o ser usa o homem e precisa dele. Nisso, que constitui o mais próprio da técnica moderna, encontra-se oculta precisamente a possibilidade dessa experiência, e de se aprontar para possibilidades novas (HEIDEGGER, 1997, p. 234).

O caminho para a libertação do jugo da técnica passa, na verdade, por uma nova postura do homem perante o ser, até então obscurecido pela hegemonia da vontade de querer, o ápice do desenvolvimento da metafísica. Segundo Heidegger, é necessário que o homem se dê conta de sua relação de dependência com o ser para que uma nova senda se lhe mostre e abra a possibilidade de liberdade de si mesmo e do real como um todo, ensejando, assim, a abertura para o que o filósofo chamou de "novo início" (HEIDEGGER, 2013).

\section{II - Da técnica à TÉXVๆ e à possibilidade de um novo início}

Heidegger discute a possibilidade de uma resposta à supremacia da técnica como fundamento do real em textos de fases distintas de seu pensamento. Na maioria deles o que se percebe é que o pensador entende o período como uma transição para o que chama de "novo início". Na coletânea de notas a textos do final da década de 1930 intitulada $O$ acontecimento apropriativo, o filósofo alemão afirma ser independente do homem a possibilidade de reviravolta do quadro contemporâneo: 
De maneira imediata, o homem pode pensar em quebrar a vontade de vontade. Isso significaria, contudo, assenhorar-se do próprio seer ${ }^{4}$ e querer dirigi-lo. Nenhum ente, tampouco aquele ente que tem a essência histórica a partir da ligação do seer com ele, o homem, pode algum dia efetuar e determinar o ser. Mas o homem histórico e sua respectiva verdade só acontecerão apropriativamente de maneira inicial a partir do seer (HEIDEGGER, 2013, p. 91).

De fato, a "salvação" do real não depende do homem, mas passa, necessariamente, por ele. No pensamento de Heidegger, desde os textos da época de Ser e tempo, encontra-se, mesmo que em estado de crisálida, a noção de acontecimento apropriador (Ereignis), que, contudo, só viria a se consolidar após a chamada "viragem" na obra do filósofo alemão. Em Tempo e ser, Heidegger define assim o Ereignis:

No destinar do destino do ser, no alcançar do tempo, mostra-se um apropriarse trans-propriar-se do ser como presença e do tempo como âmbito do aberto, no interior do que lhes é próprio. Aquilo que determina a ambos, tempo e ser, o lugar que lhes é próprio, denominamos das Ereignis (HEIDEGGER, 1973, p. 267).

É da alçada do acontecimento-apropriador a prerrogativa de dispor ser e tempo no destino de realização do ser no ente. Este destino, isto é, esse caminho, se dá, necessariamente, por meio de uma apropriação do homem, cujo próprio se constitui em deixar tempo e ser

\footnotetext{
${ }^{4} \mathrm{O}$ tradutor da passagem, Marco Antônio Casanova, explica, na nota de tradução do termo "seer" em lugar de ser na versão para o português de $O$ acontecimento apropriativo, que a palavra "remete-nos a um recurso utilizado por Heidegger a partir da década de 1930 para diferenciar a questão metafísica acerca do ser como a pergunta sobre o ser do ente na totalidade do pensamento interessado em colocar pela primeira vez a verdade do próprio ser em questão. Enquanto a metafísica compreende o ser como ente supremo e como fundamento último da realidade, o pensado voltado como possibilidade de um outro início do pensar aquiesce radicalmente à impossibilidade de transformar o ser em objeto de tematização e procura acompanhar o ser em seus acontecimentos históricos. Para marcar mais diretamente essa diferença, Heidegger cria uma distinção pautada no modo arcaico de escrita do verbo ser em alemão (Seyn), o modo de escrita que ainda era usual em autores como Fichte, Schelling e Hegel. Surgem, assim, os termos "Sein" e "Seyn". Nós traduzimos esses termos por "ser" e "seer" em função do fato de a grafia arcaica de ser em português ser feita com duas letras "e". Quanto a este fato cf. MAGNE, A. A demanda do Santo Graal. Rio de Janeiro: Imprensa Nacional, 1944, p. 37-39, entre outras". Cf. HEIDEGGER, M. O acontecimento apropriativo. Rio de Janeiro: Forense Universitária, 2013, p. 2-3.
} 


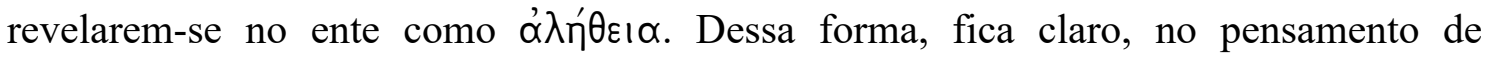
Heidegger, que o homem não muda a história e muito menos tem o poder de dominar o real, restando-lhe, no máximo, a possibilidade de ser o meio de o destino da história se realizar no fenômeno do acontecimento-apropriador através do jogo do ser e do tempo. O fim do último estágio da metafísica - a era da técnica moderna - depende da "vitória" desta configuração.

Em A questão da técnica, Heidegger apresenta uma primeira tese acerca da possibilidade de salvação do perigo de o desencobrimento do real se reduzir à disponibilidade resultante do interesse da vontade de querer em explorar e armazenar os recursos naturais, esvaziando, dessa forma, quaisquer outras possibilidades de presentificação dos entes, ou seja, de sua aparição ao homem. Para o pensador, seguindo um poema de Hölderlin ${ }^{5}$, a salvação brota do mesmo local de onde emana o perigo (HEIDEGGER, 2002a, p. 31). É da própria origem da essência da técnica moderna - a T'́X $\chi \nu \eta$ - que se entreabre a possibilidade de superação de sua hegemonia. Originalmente, TÉXVп não remete apenas à habilidade artesanal, mas ao empreender das belas artes. $\mathrm{O}$

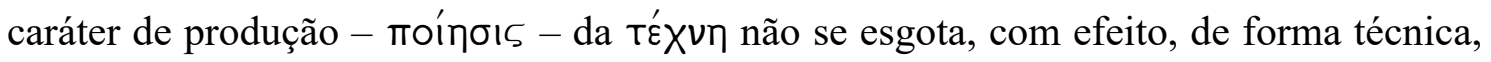
abrindo-se também e, sobretudo do ponto de vista poiético. Diante desta "ambiguidade"

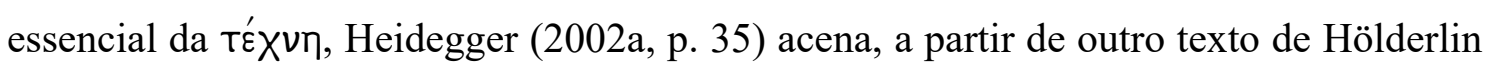
que vem a ser título de uma conhecida conferência ${ }^{6}$ do filósofo, com a possibilidade de ser a arte o caminho para a ruptura com a lógica da técnica moderna:

\begin{abstract}
Não sendo nada de técnico a essência da técnica, a consideração essencial do sentido da técnica e a discussão decisiva com ela têm de dar-se num espaço que, de um lado, seja consanguíneo da essência da técnica e, de outro, lhe seja fundamentalmente estranho. A arte nos proporciona um espaço assim. Mas somente se a consideração do sentido da arte não se fechar à constelação da verdade (HEIDEGGER, 2002a, p. 37).
\end{abstract}

Para Heidegger, apenas a arte é capaz de libertar o homem da prisão da técnica e de seu interesse equalizador. A ideia de que o real se resume à matéria de exploração e consumo só pode ser quebrada se, de alguma forma, a produção da técnica for entendida poeticamente. A TÉXVๆ deve deixar seu caráter poético suplantar o técnico para que o real volte a reinar em seu ser como verdade. Na concepção de Heidegger, a arte é a dimensão

\footnotetext{
5 “Ora, onde mora o perigo/ é lá que também cresce/ o que salva".

6 “... poeticamente, o homem habita esta terra".
} 
humana por excelência e, portanto, do ser do ente que emula o acontecimento de $\phi u ́ \sigma ı s$ no exercício próprio de sua essência. Neste sentido, a poesia, para o pensador alemão, se mostra como tendo a primazia da presentificação do ser dos entes porque o homem, modo

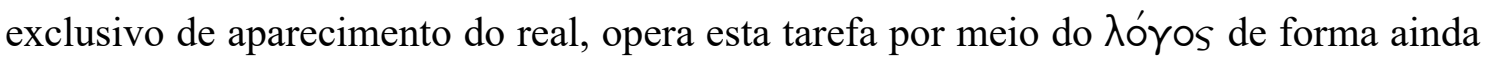
mais originária num horizonte poetizante: "a palavra mais antiga para o poder da palavra, entendido como dizer, é $\lambda o ́ \gamma o s$, que num mostrar deixa o ente aparecer em seu 'é', 'há', 'dá-se'”, diz Heidegger (2003a, p. 188) em A palavra, conferência proferida em um encontro de 1958. De fato, o real é o que é porque o homem o abre na linguagem ${ }^{7}$ e a poesia, diferente da "lógica" da metafísica, não infunde ao ente "essências fixas", mas, ao contrário, o liberta para suas inúmeras possibilidades de aparecimento - $\alpha \lambda \eta \theta \varepsilon \cup ́ \varepsilon ı \nu$. Para o filósofo, e o ao lado ou em parceria com o pensar, nenhum afazer humano diz mais o digno de expressar o ser do que o poetar. Foi com o objetivo de demonstrar esta tese que Heidegger elaborou, em sua Carta Sobre o Humanismo, esta já clássica passagem:

A linguagem é a casa do ser. Em sua habitação, mora o homem. Os pensadores e poetas lhe servem de vigias. Sua vigília é consumar a manifestação do ser, porquanto, por seu dizer, a tornam linguagem e a conservam na linguagem (HEIDEGGER, 1995, p. 24-25).

Dessa forma, apenas a abertura de um "caminho de uma construção pensante, poética" (HEIDEGGER, 2002b, p. 86) pode libertar o homem da idade da técnica para aquilo lhe é mais próprio: ser o elemento de aparecimento - desencobrimento - espontâneo e múltiplo do ser no ente.

Devolver a liberdade humana ao seu caráter ontológico mais próprio seria, no entanto, exercer aquilo que Heidegger chamou de superação da metafísica em diversos textos de sua extensa obra. Esta superação não indica uma aniquilação do pensamento metafísico, mas a sua recondução ao início, à origem esquecida e instaurada por sua instalação. Heidegger entende o período que liga Platão e Aristóteles ao estabelecimento da técnica como uma transição entre dois inícios que, não obstante serem distantes cronologicamente são, ontologicamente, o mesmo, ou seja, remetem ao próprio ser e à sua verdade, que não cessam de ser, independentemente das ações humanas. A transição,

\footnotetext{
${ }^{7}$ No Parmênides, Heidegger afirma que “'descobrir' se refere à ação do homem de falar e perceber”. A verdade entendida como $\alpha \lambda \eta^{\prime} \theta \varepsilon ı \alpha$ só é possível por meio do $\lambda o ́ \gamma o s$. Cf. HEIDEGGER, M. Parmênides. Petrópolis, RJ/Bragança Paulista, SP: Vozes/São Francisco, 2008, §3, p.64.
} 
entendida como metafísica, escalada historial da vontade de vontade, não eliminou o princípio, mas apenas o obscureceu em um período histórico de domínio da entidade do ente sobre o ser, abandonado e esquecido. Superar este longo momento da história e que encontra seu acabamento com a técnica moderna, é estabelecer um retorno ao que o pensador alemão chamou de "primeiro início", "princípio" ou "origem", exposto por Parmênides, Heráclito e Anaximandro, denominados, por esta mesma razão de "originários" por Heidegger.

Se por um lado o autor de Ser e tempo entende a arte - a poesia, mais especificamente - como o caminho mais eficaz para a chegada do "outro início" e para a superação definitiva do domínio da técnica, por outro, o pensador alemão não sabe como e quando essa reviravolta pode vir a ocorrer efetivamente. Na entrevista concedida à revista Der Spiegel, Heidegger, que concordou em falar com a publicação desde que o depoimento só fosse publicado após a sua morte (1976), se mostrou pouco otimista em relação ao quadro ontológico contemporâneo e também acerca do pretenso papel da filosofia em meio à situação atual:

\begin{abstract}
a filosofia não poderá produzir um efeito imediato que mude o estado presente do mundo. Isso vale não apenas para a filosofia, mas para tudo o que são preocupações e aspirações por parte do homem. Somente um deus ainda nos pode salvar. Resta-nos como única possibilidade preparar no pensamento e na poesia uma disponibilidade para a aparição desse deus ou para a ausência do deus no nosso declínio (HEIDEGGER, 1997, p. 233).
\end{abstract}

Heidegger já havia discutido as limitações da filosofia em relação ao quadro atual contemporâneo em A superação da metafísica (HEIDEGGER, 2002b, p. 72), ao defender que o filosofar era insuficiente para a tarefa por ter ele mesmo sucumbido à técnica e depois por já ter esgotado todo o âmbito de possibilidades a ele aberto. É provável que a sucumbência em questão remeta à vinculação da filosofia aos modelos e requisitos tecnocientíficos da academia e que a subvertem em seu princípio ao impor-lhe um produtivismo que lhe é essencialmente estranho, a despeito da rápida adesão dos "filósofos" atuais a esta lógica. No momento presente, nenhum discurso poderia representar ameaça ao mundo técnico. A arte, vislumbrada por Heidegger treze anos antes da entrevista a Der Spiegel em A questão da técnica como única forma possível de subversão do perigo da uniformização ôntica promovida pela técnica, mantém este estatuto no depoimento à revista, mas acrescenta àquela argumentação o fato de depender 
do extra-ordinário para que tal ocorra. Por esta razão afirma categoricamente que "somente um deus pode nos salvar". É interessante pontuar como reação a esta declaração algo oracular, a insistência do entrevistador no contrário e a dificuldade em perceber, como faz frequentemente o senso comum, a situação que o mundo técnico impôs ao homem, crendo estar "tudo bem". No primeiro caso, ele afirma, tentando contra argumentar, que "vivemos no conforto" e que "tudo funciona". Qual seria o problema, então? A resposta de Heidegger é eminentemente filosófica: "É muito inquietante que funcione, e que esse funcionamento arraste sempre um novo funcionamento. [...] o desenraizamento do homem já está aí. Já não é em uma Terra que o homem vive hoje" (HEIDEGGER, 1997, p. 232). O homem atual não percebe que o mundo contemporâneo se apresenta, segundo a tecnologia, tão cindido quanto aquele da metafísica clássica. Afinal, como compreender de outro modo a massiva fuga para meios virtuais, sustentados, obviamente, pela tecnologia imposta pela lógica da técnica? Em A superação da metafisica, Heidegger diz que a técnica cria "substitutivos" para preencher o vazio do real e se consolidar como "sujeito" (HEIDEGGER, 2002b, p. 83). Todos os equipamentos tecnológicos em voga na atualidade se orientam para este sentido. A priorização do virtual em detrimento do real ou mesmo a tentativa de substituição de um pelo outro por boa parte das pessoas do globo - como acontece nas redes sociais - já é um claro indício de que algo não vai bem na relação do homem com a vida. Não é à toa que, quando questionado sobre o papel da filosofia nesta configuração contemporânea, o pensador repete o que já havia dito em conferências e textos prévios - que a filosofia chegou ao fim e nada pode diante da técnica - e que, em seu lugar, se apresenta um novo "pensamento": a cibernética (HEIDEGGER, 1997, p. 235), uma vez que o lugar que já foi da filosofia, hoje, "dissolve-se em ciências particulares: a psicologia, a lógica e a politologia" (HEIDEGGER, 1997, p. 235) que são movidas pelos próprios mecanismos técnicos. A cibernética, como a compreendia Heidegger em 1966, talvez fosse uma nova linguagem capaz de atravessar e explicar todos os domínios do âmbito tecnológico sem, contudo, colocá-lo em risco, sendo, antes, um novo sustentáculo à sua dominação irrestrita. Seria algo hoje como a internet e o poderio de empresas como Google, Twitter e Facebook, cujas existências não poderiam ter sido previstas pelo filósofo alemão ou 
mesmo pela Escola de Frankfurt, cujos trabalhos, mesmo com viés mais social, denunciaram o problema ao discutir o conceito de indústria cultural $^{8}$.

Somado a esta situação está o fato de, segundo Heidegger, não haver nenhum grande pensador que recoloque o pensamento em seu caminho na contemporaneidade. Ele mesmo, a despeito da afirmação do entrevistador de Der Spiegel de que sua postura seria desencorajadora, se vê como impotente diante da supremacia hodierna da técnica:

não posso fazê-lo, porque as questões são tão difíceis que isso iria contra o sentido da tarefa do pensamento, a de fazer uma espécie de declaração oficial, de sermão, e distribuir notas de moralidade (HEIDEGGER, 1997, p. 237).

O máximo que se pode fazer é "ousar dizer isto: ao segredo da hegemonia planetária do ser impensado da técnica corresponde o caráter provisório e inaparente do pensamento que tenta pôr-se em busca do impensado" (HEIDEGGER, 1997, p. 237).

A reação do entrevistador aponta para a dificuldade que o pensamento contemporâneo tem em compreender - e aceitar - o caráter dependente do homem em relação ao real e as incertezas que permeiam a existência. Afinal, a vontade que dispõe a metafísica se crê como onipotente e o mundo contemporâneo é ele mesmo o resultado desta crença. A impotência que o filósofo admite, contudo, em sua resposta, apenas demonstra que não há nada que o homem possa fazer imediatamente e de forma cabal. $\mathrm{O}$ que ele pode - e, por isso, deve - fazer é "esperar o inesperado", como dizia Heráclito. Esta espera, que é, no fundo, uma ausculta, não é passiva ou ativa, conceitos insuficientes para a compreensão da situação. A espera deve motivar um pensar elaborado no silêncio, pois este é a única barreira para o ruído do falatório ${ }^{10}$ nivelador e esvaziador do mundo contemporâneo. Nietzsche (2011, p. 140) já dizia no Zaratustra que "as palavras mais

\footnotetext{
${ }^{8}$ Neste particular, destacam-se Theodor Adorno e Max Horkheimer, na Dialética do esclarecimento, e Herbert Marcuse em sua Sociedade industrial - o homem unidimensional.

${ }^{9}$ Fragmento 18: "Se não esperar, não encontrará o inesperado, sendo não encontrável e inacessível". Cf. HERÁCLITO. Fragmentos contextualizados. São Paulo: Odysseus Editora, 2012, p. 53.

${ }^{10}$ A noção de "falatório" utilizada aqui é aquela mesma empregada por Heidegger no $§ 35$ de Ser e tempo para descrever o modo de ser cotidiano do discurso, a saber, aquele que apenas se limita a repetir e passar adiante o que foi recebido por meio do discurso sem, contudo, participar de sua proveniência ontológica. O falatório constitui, por exemplo, a fala dos meios de comunicação de massa e sua difusão social.
} 
quietas são as que trazem a tempestade. Pensamentos que vem com pés de pombas dirigem o mundo". Esse pensar depende, contudo, de uma nova relação com a técnica que não visa eliminá-la, mas apenas devolver-lhe aquilo lhe é ontologicamente de direito.

Em um texto de 1959, intitulado Serenidade, Heidegger sugere dar um "sim" e um "não" simultâneos à técnica por meio de um olhar sereno sobre o fenômeno e não de deslumbramento, como se observa na atualidade:

deixamos os objetos técnicos entrar no nosso mundo cotidiano e ao mesmo tempo deixamo-los fora, isto é, deixamo-los repousar em si mesmos como coisas que não são algo de absoluto, mas que dependem elas próprias de algo superior (HEIDEGGER, 2000, p. 24).

Afinal, todo o problema da técnica reside, justamente, no caráter absolutizante de sua estrutura. Os objetos da técnica, desde que o homem começou a criar instrumentos para si na tentativa de compreensão da natureza, sempre fizeram parte de suas ações. Por mais que pareça ao um olhar incauto, o desejo de Heidegger não é o de eliminar a técnica da face da Terra, mas reconduzi-la ao seu próprio para que o homem possa igualmente retornar à sua essência. A técnica deve voltar a ser um conjunto de instrumentos para a interação entre homem e natureza e não de domínio desta por meio daquele. O que se vê hoje é, com efeito, a dominação da técnica, isto é, das máquinas, telas e demais equipamentos sobre um homem preso ao trabalho e à necessidade imperiosa de produzir mesmo sem um sentido existencial definido. A possibilidade de aparecimento do extraordinário que poderá reordenar o real depende, contudo, da defesa do homem e de sua essência, por meio da qual o novo pode, efetivamente, irromper:

\begin{abstract}
a revolução da técnica que se está a processar na era atômica poderia prender, enfeitiçar, ofuscar e deslumbrar o homem de tal modo que, um dia, o pensamento que calcula viesse a ser o único pensamento admitido e exercido. [...] Então o homem teria renegado e rejeitado aquilo que tem de mais próprio, ou seja, o fato de ser um ser que reflete. Por isso é importante salvar essa essência do homem. Por isso o importante é manter desperta a reflexão (HEIDEGGER, 2000, p. 26).
\end{abstract}

O homem precisa resguardar o seu próprio, ou seja, o fato de estar aberto para o seu aí, a clareira para que o ser possa por meio dele se manifestar no ente. O real depende do

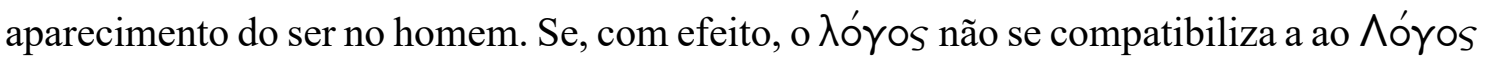

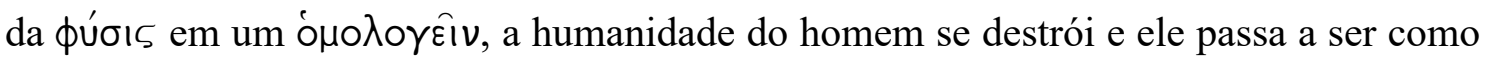


qualquer outro ente, à espera de uma "iluminação" de fora. O mundo contemporâneo, com o incremento do trabalho para a produtividade e do entretenimento como válvula de escape para o tédio consequente desta configuração, asfixia o ócio e, com isso, a possibilidade de emergência de um pensar genuíno. Se nada, contudo, pode ser feito, mas, ao contrário, depender dos movimentos da história do próprio ser, isto é, de sua verdade via acontecimento apropriativo, ao homem, local de aparecimento desta possibilidade de mudança - o extraordinário -, cabe esperar na ausculta do pensar que resguarda o ente enquanto possibilidade múltipla de mostração - $\alpha \lambda \eta \dot{\theta} \theta \varepsilon \_$- e não aceitar reduzir-se livremente à pura matéria para exploração e armazenamento dos recursos da natureza fomentados pelo binômio consumo-trabalho.

O extraordinário, a propósito, é o que Heidegger chamou de "deus" e que, para ele, se mostra como a única forma de salvar o homem de sua atual condição. Com efeito, os deuses deixaram o homem no momento em que este abandonou o ser em detrimento do ente: "a fuga dos deuses gregos funda-se na perturbação da essência quase não desentranhada da $\alpha \lambda \eta^{\prime} \theta \varepsilon ı \alpha$. A penetração do ser como i $\delta^{\prime} \varepsilon$ é o fim do tempo dos deuses" (HEIDEGGER, 2013, p. 228). O estabelecimento da metafísica afugentou as divindades que, no entender de Heidegger, dependem do ser na mesma medida em que o ser precisa do homem para aparecer em sua verdade. Se o homem esquece o ser, este e os deuses desaparecem. Em Contribuições à filosofia (do acontecimento), obra que reúne anotações de Heidegger elaboradas entre 1936 e 1938, o filósofo mostra que há uma estreita relação entre ser, homem e deuses:

\footnotetext{
O acontecimento consigna deus ao ser humano ao designar o ser humano a deus. Esta consignação designadora é o acontecimento apropriador; nele, a verdade do seer é fundada como ser-aí (e o ser humano é transformado, colocando-se na decisão de ser-aí ou ser-fora), e a história recebe seu outro início do seer (HEIDEGGER, 2012a, p. 23).
}

Se "somente um deus pode ainda nos salvar", como afirmou Heidegger à Der Spiegel, este salvamento depende, contudo, de uma preparação do próprio homem para este possível evento. O deus - ou o "último deus", aquele "do primeiro início e o deus supremo" e "que funda a essenciação daquilo que, mal computado, se chama eternidade" (HEIDEGGER, 2013, p. 228) não poderá aparecer sem a pré-disposição do homem à sua chegada. Aqui não cabe voluntarismo, mas "preparar no pensamento e na poesia uma disponibilidade para a aparição desse deus" (HEIDEGGER, 1997, p. 233), que abre a 
possibilidade de ruptura com a lógica da redução do real à disponibilidade dos entes à mera exploração e consumo por meio de uma vontade de controle. Destarte, este deus, que nada tem a ver com o cristão, não solicita "esperança", mas "preparação" para seu advento:

\begin{abstract}
Quantos poucos sabem que o deus espera a fundação da verdade do seer e assim espera o salto do ser humano no Da-sein! Parece, ao contrário, que o ser humano deveria e teria que de esperar pelo deus. Talvez esta seja a mais traiçoeira forma da mais profunda falta de deus. Talvez seja também a letargia da incapacidade de submeter a apropriação da intervenção do "aí" do seer que primeiro oferece um lugar para o abrigo (descanso) na verdade e concede a eles o privilégio de permanecer nos mais distantes recônditos da passagem do deus. A concessão deste privilégio acontece apenas como história: na transformação dos entes na essencialidade da sua determinação e na sua liberação do ente abusado pelas maquinações que pervertem tudo e exaurem entes com vistas ao ganho. (HEIDEGGER, 2012a, p. 330).
\end{abstract}

Em outras palavras, o deus só poderá salvar a humanidade do esvaziamento ontológico produzido pela técnica se o homem estiver preparado, ou seja, pré-disposto a seu aparecimento por meio da ação do pensamento e da arte (poesia), que permitem que novas possibilidades de desencobrimento rompam a ditadura da disponibilidade técnica dos entes como matéria de exploração e consumo. Esta possível reconfiguração é uma condução ao que Heidegger chamou de "outro início", ou seja, ao estabelecimento de um

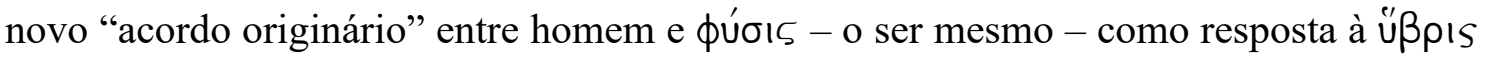
que instalou a metafísica e abandonou o ser por meio da atividade do querer infinito da vontade. Nesta perspectiva, Heidegger pensa a história do ser como dividida em dois inícios e uma transição. Esta é o período de domínio da entidade do ente como fundamento do real:

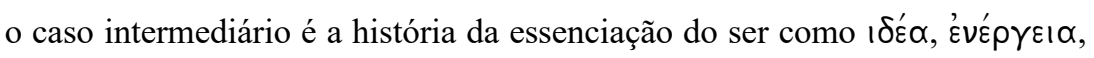
actus, perceptio, realidade efetiva, representação, que reúne para si figuras essenciais da vontade de vontade. $\mathrm{O}$ caso intermediário encontra-se entre $\mathrm{o}$ primeiro e o outro início. Por meio desse caso intermediário, a inicialidade do início chega à primeira ressonância (HEIDEGGER, 2013, p. 108).

A metafísica é um "entre" que separa a inicialidade do início em dois momentos da história. O início - o reino do ser, contudo, sempre já esteve aí, embora encoberto pela üßpıs da vontade do homem ocidental de ser princípio e fundamento. Esta presunção instala a metafísica e oblitera a visão do homem em sua relação com o real, rebaixando este último ao falso, ao imperfeito e ao engano no momento em que instaura o domínio 
da entidade que se desenvolve nas formas de Deus e cogito. $\mathrm{O}$ acabamento da metafísica - a idade da técnica - marca simultaneamente o ápice do obscurecimento do ser e também a possibilidade de aparecimento de um novo início, marcado por uma igualmente nova postura humana que possibilita a chegada do deus que pode salvar o homem do jugo da tecnologia e devolver-lhe a vinculação ao ser que caracteriza sua verdadeira essência. Cabe ao homem, contudo, dispor-se para o acontecimento.

\section{Referências bibliográficas}

ADORNO, T.; HORKHEIMER, M. Dialética do Esclarecimento. Rio de Janeiro: Zahar, 1991.

CLUBE DA LUTA. Direção: David Fincher. Intérpretes: Brad Pitt; Edward Norton; Helena Bonham Carter. [SI]: 20th Century Fox, 1999. 1 Blu-ray (138 min), son., color.

FOGEL, G. Da solidão perfeita. Petrópolis: Vozes, 1999.

GILSON, E. Études sur le rôle de la pensée médiévale dans la formation du système cartésien. Paris: Vrin, 1930.

HEIDEGGER, M. A palavra. In: A caminho da linguagem. Petrópolis: Vozes, 2003a.

- A questão da técnica. In: . Ensaios e conferências.

Petrópolis: Vozes, 2002a.

. A superação da metafísica. In: . Ensaios e conferências. Petrópolis: Vozes, $2002 \mathrm{~b}$.

Contributions to philosophy (of the event). Bloomington: Indiana University Press, 2012a.

. Heráclito. Rio de Janeiro: Relume Dumará, 2002.

. Le mot de Nietzsche "Dieu est mort". In: . Chemins qui ne mènent nulle part. Paris: Gallimard, 2002c.

Martin Heidegger entrevistado por Der Spiegel. In: Escritos políticos 1933 - 1966. Lisboa: Instituto Piaget, 1997. . Nietzsche. Vol I e II. San Francisco: Harper Collins, 1991. 
| Dossiê | Heidegger e a técnica como acabamento da metafísica e possibilidade de um novo início |

O acontecimento apropriativo. Rio de Janeiro: Forense Universitária, Francisco, 2008

- Parmênides. Petrópolis, RJ/Bragança Paulista, SP: Vozes/São . Plato's sophist. Indiana: Indiana University Press, 2003b.

$2012 \mathrm{~b}$ . Ser e tempo. Campinas: Editora Unicamp; Petrópolis: Editora Vozes, . Serenidade. Lisboa: Instituto Piaget, 2000. . Sobre o humanismo. Rio de Janeiro: Tempo Brasileiro, 1995.

Cultural, 1973. . Tempo e ser. In: Heidegger - Os pensadores. São Paulo: Nova HERÁCLITO. Fragmentos contextualizados. São Paulo: Odysseus Editora, 2012.

MARCUSE, H. A Ideologia da Sociedade Industrial - O Homem Unidimensional. Rio de Janeiro: Zahar, 1973.

MARX, K. Manuscritos econômicos-filosóficos. Lisboa: Edições 70, 1993.

MATRIX. Direção: Lana Wachowski e Lilly Wachowski. Intérpretes: Keanu Reeves; Laurence Fishburne; Carrie-Anne Moss; Hugo Weaving. [SI]: Warner Bros., 1999. 1 Bluray (136 $\mathrm{min})$, son., color.

NIETZSCHE, F. A vontade de poder. Rio de Janeiro: Contraponto, 2008. . Assim falou Zaratustra. São Paulo: Companhia das Letras, 2011.

STEIN, E. Introdução ao pensamento de Martin Heidegger. Porto Alegre: EdiPUCRS, 2011.

Recebido em: 02/10/2020 | Aprovado em: 06/10/2020 